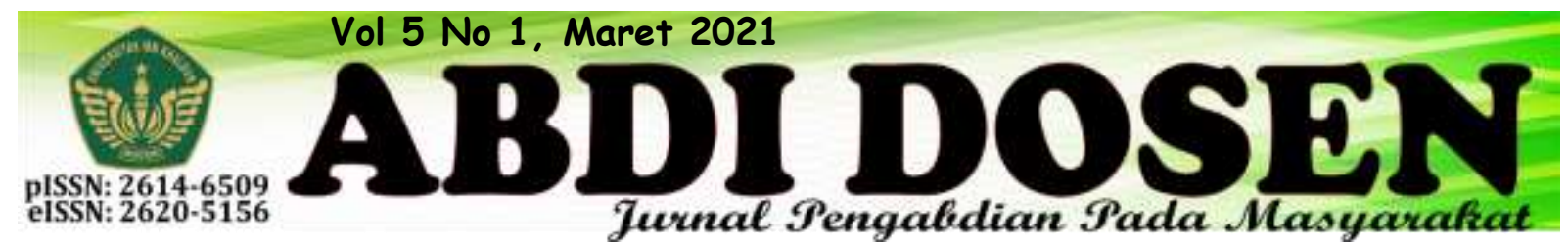

\title{
LATIHAN RELAKSASI OTOT PROGRESIF UNTUK MENURUNKAN TEKANAN DARAH PENDERITA HIPERTENSI DI RT 13 KELURAHAN 29 ILIR KECAMATAN ILIR BARAT II WILAYAH KERJA PUSKESMAS MAKRAYU PALEMBANG
}

\author{
Azwaldi $^{1}$, Rumentalia ${ }^{2}$, Imelda Erman $^{3}$ \\ azwaldi@poltekkespalembang.ac.id ${ }^{1}$ \\ rumentalia@poltekkespalembang.ac.id ${ }^{2}$ \\ imelda@poltekkespalembang.ac.id ${ }^{3}$ \\ Prodi D IV Keperawatan, Politeknik Kesehatan Kementerian Kesehatan Palembang 1,2,3
}

\begin{abstract}
ABSTRAK
Angka kejadian hipertensi semakin meningkat setiap tahunnya. WHO memperkirakan tahun 2025 terdapat 1,15 milyar kasus atau sekitar 29\% dari total penduduk dunia menderita hipertensi, dimana 333 juta berada di negara maju dan 639 sisanya berada di negara berkembang, termasuk di Indonesia. Kejadian hipertensi yang meningkat setiap tahunnya mengindikasikan bahwa hipertensi perlu dan harus segera diatasi. Oleh sebab itu, penanganan hipertensi berupa pengobatan maupun perawatan dini sangat penting karena hipertensi merupakan suatu penyakit kronis yang harus dikontrol seumur hidup. Kegiatan ini bertujuan memberi pelatihan relaksasi otot progresif untuk mengurangi ketegangan atau kecemasan dengan menciptakan suasana dan perasaan relaks bagi penderita hipertensi, sehingga menurunkan tekanan darah penderita hipertensi. Metode kegiatan berupa demonstrasi, latihan pemeriksaan tekanan darah sebelum dan setelah latihan relaksasi otot progresif dan pendidikan kesehatan. Hasil Kegiatan menunjukkan penurunan tekanan darah sebesar 10-15 mmHg setelah dilakukan latihan relaksasi otot Progresif.
\end{abstract}

Kata Kunci : Latihan Relaksasi Otot Progresif, Tekanan Darah, Hipertensi

\section{ABSTRACT}

The incidence of hypertension is increasing every year. WHO estimates that by 2025 there will be 1.15 billion cases or around $29 \%$ of the world's total population suffering from hypertension, of which 333 million are in developed countries and the remaining 639 are in developing countries, including Indonesia. The incidence of hypertension that increases every year indicates that hypertension needs and must be addressed immediately. Therefore, the management of hypertension in the form of medication and early treatment is very important because hypertension is a chronic disease that must be controlled for life. This activity aims to provide progressive muscle relaxation training to reduce tension or anxiety by creating a relaxed atmosphere and feeling for people with hypertension, thereby reducing blood pressure for people with hypertension. Methods of activity include demonstrations, blood pressure check exercises before and after progressive muscle relaxation exercises and health education. Activity results showed a decrease in blood pressure of 10-15 $\mathrm{mmHg}$ after progressive muscle relaxation exercises.

Keywords: Progressive Muscle Relaxation Exercise, Blood Pressure, Hypertension 


\section{PENDAHULUAN}

Hipertensi merupakan salah satu penyakit tidak menular yang sering disebut dengan "sillent killer" atau pembunuh diam-diam karena pada umumnya, seseorang dapat mengidap penyakit ini selama bertahun-tahun tanpa menyadarinya sampai terjadi kerusakan organ vital. Kerusakan organ-organ target yang umum ditemui adalah jantung (penyakit jantung koroner, disritmia, dan gagal jantung), otak (stroke, encephalophaty), ginjal (nefrosklerosis, insufiensi), arteri perifer dan retinopati. Hipertensi juga meningkatkan resiko serangan stroke empat kali lebih besar serta dua kali lebih besar terkena penyakit gagal jantung dibandingkan dengan orang yang mempunyai tekanan darah normal (LeMone \& Burke, 2008). Angka kejadian hipertensi semakin meningkat setiap tahunnya. World Health Organization (WHO) pada tahun 2013 mencatat sedikitnya telah terjadi sebanyak 972 juta kasus hipertensi di seluruh dunia dan dapat diperkirakan menjadi 1,15 milyar kasus pada tahun 2025 atau sekitar $29 \%$ dari total penduduk dunia menderita hipertensi, dimana 333 juta berada di negara maju dan 639 sisanya berada di negara berkembang, termasuk di Indonesia (Triyanto, 2014).

Kejadian hipertensi yang meningkat setiap tahunnya mengindikasikan bahwa hipertensi perlu dan harus segera diatasi. Oleh sebab itu, Muttaqin (2012) menyebutkan penanganan hipertensi berupa pengobatan mau pun perawatan dini sangat penting karena hipertensi merupakan suatu penyakit kronis yang harus dikontrol seumur hidup. Penatalaksanaan hipertensi terdiri dari terapi farmakologis dan non farmakologis. Penatalaksanaan secara farmakologis terdiri atas pemberian obat yang bersifat diuretik, simpatik, beta bloker, dan vasodilator yang mempunyai efek samping penurunan curah jantung. Sedangkan penanganan nonfarmakologi merupakan penanganan yang meliputi penurunan berat badan, olahraga secara teratur, diet rendah garam dan lemak, serta terapi komplementar (Ramadi, 2012).

Sampai saat ini pengobatan bagi penderita hipertensi masih belum efektif karena sering terjadi kekambuhan serta menimbulkan efek samping berbahaya dalam jangka waktu yang panjang. Hal ini yang mendorong para ilmuwan untuk mengembangkan terapi non farmakologis, salah satunya yaitu terapi komplementer. Terapi komplementer banyak digunakan untuk mengatasi hipertensi karena bersifat alamiah dan tidak menimbulkan efek samping yang berbahaya. Terapi komplementer diantaranya adalah terapi relaksasi otot progresif, terapi musik, senam aerobik, dan yoga (Triyanto, 2014).

Salah satu bentuk terapi komplementer menurut Purwanto (2013) ialah latihan relaksasi otot progresif yang merupakan prosedur untuk mengurangi ketegangan atau kecemasan dengan cara melatih penderita untuk merilekskan otototot dalam tubuh. Cara yang dilakukan yaitu dengan memusatkan perhatian pada suatu aktivitas otot, dengan mengidentifikasikan otot yang tegang kemudian menurunkan ketegangan dengan melakukan teknik relaksasi untuk mendapatkan perasaan relaks. Relasksasi otot progresif dapat membantu menurunkan tekanan darah, insomnia, dan asma serta dapat melawan rasa cemas, stress, atau tegang dengan cara menegangkan dan melemaskan otot 
sehingga seseorang bisa menghilangkan kontraksi otot dan menjadi rileks (Resti, 2014).

Berdasarkan penelitian yang dilakukan oleh Tyani dkk (2015) mengenai efek latihan relaksasi otot progresif terhadap penderita hipertensi esensial yang dilakukan pada 30 responden di Puskesmas Tenayan Raya Pekanbaru didapatkan hasil signifikan rata-rata tekanan darah sistole dan diastole sebelum dan sesudah diberikan intervensi pada kelompok eksperimen. Penelitian lain yang dilakukan tentang relaksasi otot progresif terhadap tekanan darah pada pasien hipertensi primer telah dilakukan pada satu kelompok perlakuan tanpa kelompok kontrol, menunjukkan terdapat hasil yang signifikan terhadap nilai sistolik antara sebelum dilakukan relaksasi otot progresif dengan setelah dilakukan relaksasi otot progresif sehingga relaksasi otot progresif berpengaruh dalam penurunan tekanan darah (Herawati dan Azizah, 2016). Adapun penelitian yang telah dilakukan oleh Valentine et al. (2014), terbukti bahwa terapi relaksasi otot progresif dapat menurukan tekanan darah pada hipertensi primer. Berdasarkan studi pendahuluan yang telah dilakukan di Posyandu Lansia Peduli Insani Mendungan Surakarta, terdapat 78 orang yang terdiri dari 64 perempuan dan 14 laki-laki yang hadir pada kegiatan posyandu bulan November

\section{METODE PELAKSANAAN}

Metode pelaksanaan pengabdian masyarakat ini berbentuk pelatihan, demonstrasi, pendidikan kesehatan dan pemeriksaan kesehatan. Tujuan kegiatan ini adalah untuk mengetahui pengaruh latihan relaksasi Otot Progresif terhadap tekanan Darah warga dengan hipertensi di RT 13 Kelurahan 29 Ilir Kecamatan Ilir
2016. Dari 64 perempuan, terdapat 22 orang yang termasuk lanjut usia dan terdiagnosa hipertensi. Penelitian lainnya yang dilakukan oleh Azizah (2016), menunjukan bahwa latihan relaksasi otot progresif berpengaruh secara signifikan terhadap penurunan tekanan darah sistolik pada penderita hipertensi primer, sedangkan tekanan darah diastolik tidak menunjukkan adanya pengaruh terhadap tekanan darah. Terapi relaksasi otot progresif dilakukan pada lanjut usia untuk memunculkan respon relaksasi yang dapat menimbulkan keadaan tenang dan rileks sehingga terjadi penurunan tekanan darah pada lanjut usia (Adisucipto, 2014).

Tingginya angka kekambuhan yang disebabkan ketidakpatuhan dalam memakan obat farmaka atau hypertensi yang tidak terkontrol sehingga pengembangan dan penerapan terapi komplementer adalah pilihan yang tepat untuk mengatasi hipertensi karena bersifat alamiah dan tidak menimbulkan efek samping yang berbahaya. Berdasarkan penjelasan diatas dan didukung oleh berbagai data dan sumber, maka Tim Pengabdi tertarik untuk melakukan pengabmas mengenai "Latihan relaksasi otot progressive untuk menurunkan tekanan darah penderita hipertensi di RT 13 Kelurahan 29 ilir Kecamatan Ilir Barat II Wilayah Kerja Puskesmas Makrayu Palembang.

Barat II Wilayah Kerja Puskesmas Makrayu Palembang. Adapun tujuan khusus pengabdian masyarakat ini yaitu melakukan pemeriksaan umum melalui pengukuran tekanan darah sebelum dan sesudah latihan relaksasi otot, memberikaan latihan relaksasi otot Progresif, memberikan konseling dan 
pendidikan kesehatan tentang hipertensi, menurunkan tekanan darah penderita hipertensi, meningkatkan pengetahuan penderita hipertensi tentang bahaya hipertensi, serta mencegah terjadinya kompikasi Hipertensi yang lebih lanjut. Mitra kerja dalam kegiatan ini adalah; Kader Posyandu Mawar 1 Wilayah Puskesmas Makrayu, Keluarga Penderita Hipertensi, penderita hipertensi dan Ketua RT 13.

Pengabdian Masyarakat ini dilaksanakan dengan tahapan sebagai berikut :

1. Tahap pertama ; Melakukan pengukuran tekanan darah penderita hipertensi sebelum dilakukan latihan relaksasi otot Progresif

2. Tahap Kedua ; Melakukan metode demonstrasi yaitu dengan melakukan latihan relaksasi otot Progresif pada penderita hipertensi

3. Tahap Ketiga ; Melakukan pengukuran tekanan darah penderita Hipertensi setelah

\section{HASIL dan PEMBAHASAN}

Kegiatan pengabdian masyarakat ini telah terlaksana pada tanggal 28 Juli 2018 di RT 13 Kelurahan 29 Ilir Kecamatan Ilir Barat II dalam Wilayah kerja Puskesmas Makrayu dengan jumlah peserta sebanyak 27 orang. Selama pelaksanaan kegiatan pengabdian masyarakat, mulai dari tahap persiapan sampai pelaksanaan didapatkan masyarakat sangat antusias akan kegiatan ini, semua mengikuti dengan baik mulai dari kegiatan penyuluhan sampai dengan demonstrasi relaksasi otot progresif. Situasi dan kondisi kegiatan cukup kondusif dan didukung oleh sarana dan prasarana yang cukup memadai sehingga diberikan latihan relaksasi otot Progresif

4. Tahap Keempat ; Melakukan metode ceramah yaitu memberikan pendidikan kesehatan kepada penderita Hipertensi dengan media Leaflet. Diharapkan dengan tersedianya Leaflet dapat membantu penderita dalam melakukan latihan relaksasi otot Progresif selama dirumah

5. Tahap Kelima ; Melakukan metode pendampingan kepada penderita Hipertensi untuk dapat menerapkan latihan relaksasi otot Progresif selama di rumah

Tahap evaluasi dilakukan dengan menilai minat dan kesadaran penderita hipertensi untuk melaksanakan latihan relaksasi otot Progresif selama di rumah, mengevaluasi penurunan tekanan darah pada penderita hipertensi.

kegiatan ini dapat berjalan dengan lancar. Kegiatan ini melibatkan beberapa mitra kerja yaitu kader Posyandu Mawar 1 dalam wilayah kerja Puskesmas Makrayu, keluarga penderita hipertensi dan Ketua RT .

\section{a. Karakteristik Responden}

Gambaran karakteristik responden meliputi berat badan, usia, jenis kelamin, pendidikan, status perkawinan, dan riwayat hipertensi. Responden dalam kegiatan ini berjumlah 27 orang, untuk gambaran karakteristik responden akan dijelaskan sebagai berikut : 
Tabel 1. Distribusi Berat Badan dan Usia peserta $(n=27)$

\begin{tabular}{cccccc}
\hline Variabel & Mean & Median & $\begin{array}{c}\text { Standar } \\
\text { Deviasi }\end{array}$ & $\begin{array}{c}\text { Min- } \\
\max \end{array}$ & $95 \%$ CI \\
\hline $\begin{array}{c}\text { Berat } \\
\text { badan }\end{array}$ & 53,22 & 55,00 & 9,573 & $36-76$ & $49,44-57,01$ \\
\hline Usia & 62,70 & 65,00 & 11,783 & $42-83$ & $58,04-67,36$ \\
\hline
\end{tabular}

Berdasarkan tabel 1. didapatkan ratarata berat badan responden adalah $53,22 \mathrm{~kg}$ dengan median $55,00 \mathrm{~kg}$ dan standar deviasi 9,573. Berat badan responden paling rendah adalah $36 \mathrm{~kg}$ sedangkan yang tertinggi adalah $76 \mathrm{~kg}$. Dari hasil estimasi interval diyakini bahwa 95\% ratarata berat badan responden berada pada rentang 49,44 kg sampai $57,01 \mathrm{~kg}$. Ratarata usia responden adalah 62,70 tahun dengan median 65,00 tahun dan standar deviasi 11,783. Usia responden paling muda adalah 42 tahun sedangkan yang tertua adalah 83 tahun. Dari hasil estimasi interval diyakini bahwa $95 \%$ rata-rata usia responden berada pada rentang 58,04 tahun sampai 67,36 tahun.

Hasil dari kegiatan pengabdian kepada masyarakat di dukung oleh teori yang menyatakan bahwa Semakin bertambahnya usia seseorang akan menyebabkan meningkatnya tekanan darahnya.. Dimana vaskulerisasi seseorang kondisinya menurun berkaitan dengan usia seperti arterosklerosis dari arteri-arteri utama, terutama aorta dan akibat dari berkurangnya elastisitas. Dengan mengerasnya arteri-arteri ini dan menjadi semakin kaku, arteri dan aorta kehilangan daya penyesuaian diri (Hanns Petter, 2009 dalam Fuad, 2012). Pengabdi berpendapat, semakin bertambah usia seseorang maka akan semakin meningkat tekanan darahnya. Hal ini berkaitan dengan penurunan elastisitas pembuluh darah seiring dengan pertambahan usia seseorang.

Tabel 2. Distribusi Frekuensi Berdasarkan Jenis Kelamin, pendidikan, status perkawinan (n=27)

\begin{tabular}{ccc}
\hline Variabel & Frekuensi & Presentase (\%) \\
\hline Laki-laki & 6 & 23 \\
Perempuan & 21 & 77 \\
\hline Rendah & 25 & 92 \\
Menengah & 1 & 4 \\
Tinggi & 1 & 4 \\
\hline Menikah & 27 & 100 \\
Tidak Menikah & 0 & 0 \\
\hline Total & 27 & 100
\end{tabular}

Berdasarkan tabel 2. didapatkan $77 \%$ peserta pelatihan berjenis kelamin perempuan, $92 \%$ berpendidikan rendah dan $100 \%$ status peserta telah menikah.

Bila melihat data dari tingkat pendidikan responden dimana sebagian 
besar adalag berpendidikan rendah, maka kondisi ini dapat menyebabkan kurangnya tingkat pemahaman akan penyakit Hipertensi. Menurut Ketut Gama et al (2014) dalam Wahyudi dkk (2017) menyatakan semakin tinggi pendidikan seseorang, maka akan memudahkan seseorang untuk menerima informasi sehingga meningkatkan kualitas hidup dan menambah luas pengetahuan. Di dukung juga oleh Wahyuni dan Eksanoto (2013) tentang hubungan tingkat pendidikan dan jenis kelamin dengan kejadian hipertensi di Kelurahan Jagalan di Wilayah Kerja Puskesmas Pucangsawit Surakarta. Dari penelitian tersebut, didapatkan hasil bahwa sebanyak 165 orang $(79,71 \%)$ berpendidikan rendah, 20 orang $(9,66 \%)$ berpendidikan menengah, dan 22 orang $(10,62 \%)$ berpendidikan tinggi. Pengabdi berpendapat, tingkat pendidikan seseorang akan mempengaruhi tingkat pemahaman, keluasan akses informasi dan relative tinggi social ekonominya baik, sehingga akan berdampak terhadap pola prilaku atau life style dalam kehidupannya, semakin rendah pendidikan seseorang, maka kemungkinan untuk menderita hipertensi juga akan semakin tinggi, begitu pula sebaliknya. Oleh karena itu untuk mengantisipasi mispersepti teradap latihan yang diberikan, maka tim pengabmas melakukan demonstrasi, penayangan video, dan melakukan redemontrasi agar peserta pelatihan dapat menangkap dengan baik latihan relaksasi otot progresif ini.

Tabel 3. Distribusi Frekuensi Berdasarkan Riwayat Hipertensi ( $n=27)$

\begin{tabular}{ccc}
\hline Riwayat Hipertensi & Frekuensi & Presentase (\%) \\
\hline Hipertensi & 14 & 51,8 \\
Tidak Hipertensi & 13 & 48,2 \\
\hline Total & 27 & 100 \\
\hline
\end{tabular}

Berdasarkan tabel 3. didapatkan 51,8\% responden memiliki riwayat penyakit hipertensi.

\section{b. Tekanan Darah Sistolik dan Diastolik Sebelum Dilakukan Latihan Relaksasi Otot Progresif}

Tabel 4. Deskriptif Tekanan Darah Sistolik dan Diastolik Sebelum Dilakukan Latihan Relaksasi Otot Progresif

\begin{tabular}{cccccc}
\multicolumn{6}{c}{$(\mathrm{n}=27)$} \\
\hline \multirow{2}{*}{ Variabel } & Mean & Median & $\begin{array}{c}\text { Standar } \\
\text { Deviasi }\end{array}$ & $\begin{array}{c}\text { Min- } \\
\max \end{array}$ & $95 \%$ CI \\
\hline \multirow{2}{*}{ Sistolik } & 136,30 & 130,00 & 21,865 & 200 & 144,95 \\
Diastolik & 85,19 & 80,00 & 11,222 & $70-$ & $80,75-$ \\
& & & & 100 & 89,62 \\
\hline
\end{tabular}

Berdasarkan tabel 4. didapatkan ratarata tekanan darah sistolik dan diastolik sebelum dilakukan latihan relaksasi otot progresif adalah $136,30 \mathrm{mmHg}$ dan 85,19 mmHg dengan median $130,00 \mathrm{mmHg}$ pada tekanan sistolik dan $80,00 \mathrm{mmHg}$ pada tekanan diastolik. Standar deviasi adalah 21,865 untuk tekanan darah sistolik dan 11,222 untuk tekanan darah diastolik. Tekanan darah sistolik sebelum dilakukan 
latihan relaksasi otot progresif terendah adalah $100 \mathrm{mmHg}$ dan tertinggi adalah 200 mmHg. Sedangkan untuk tekanan darah diastolik sebelum dilakukan latihan relaksasi otot progresif terendah adalah 70 $\mathrm{mmHg}$ dan tertinggi adalah $100 \mathrm{mmHg}$. Dari hasil estimasi interval diyakini bahwa
95\% rata-rata tekanan darah sistolik sebelum dilakukan latihan relaksasi otot progresif berada pada rentang 127,65 sampai $144,95 \mathrm{mmHg}$ dan untuk tekanan darah diastolik berada pada rentang 80,75 sampai 89,62 mmHg.

\section{c. Tekanan Darah Sistolik dan Diastolik Setelah Dilakukan Latihan Relaksasi Otot Progresif}

Tabel 5. Deskriptif Tekanan Darah Sistolik dan Diastolik Setelah Dilakukan Latihan Relaksasi Otot Progresif $(n=27)$

\begin{tabular}{cccccc}
\hline Variabel & \multirow{2}{*}{ Mean } & $\begin{array}{c}\text { Media } \\
\mathrm{n}\end{array}$ & $\begin{array}{c}\text { Standar } \\
\text { Deviasi }\end{array}$ & $\begin{array}{c}\text { Min- } \\
\max \end{array}$ & $95 \% \mathrm{CI}$ \\
\hline Sistolik & 128,52 & 130,00 & 21,430 & $\begin{array}{c}100- \\
190\end{array}$ & $\begin{array}{c}120,04-137,00 \\
79,53-87,13\end{array}$ \\
Diastolik & 83,33 & 80,00 & 9,608 & $70-100$ & \\
\hline
\end{tabular}

Berdasarkan tabel 5. didapatkan ratarata tekanan darah sistolik dan diastolik setelah dilakukan latihan relaksasi otot progresif adalah $128,52 \mathrm{mmHg}$ dan 83,33 mmHg dengan median $130,00 \mathrm{mmHg}$ pada tekanan sistolik dan $80,00 \mathrm{mmHg}$ pada tekanan diastolik. Standar deviasi adalah 21,430 untuk tekanan darah sistolik dan 9,608 untuk tekanan darah diastolik. Tekanan darah sistolik setelah dilakukan latihan relaksasi otot progresif terendah adalah $100 \mathrm{mmHg}$ dan tertinggi adalah 190
mmHg. Sedangkan untuk tekanan darah diastolik sebelum dilakukan latihan relaksasi otot progresif terendah adalah 70 $\mathrm{mmHg}$ dan tertinggi adalah $100 \mathrm{mmHg}$. Dari hasil estimasi interval diyakini bahwa 95\% rata-rata tekanan darah sistolik setelah dilakukan latihan relaksasi otot progresif berada pada rentang 120,04 sampai $137,00 \mathrm{mmHg}$ dan untuk tekanan darah diastolik berada pada rentang 79,53 sampai $87,13 \mathrm{mmHg}$. 

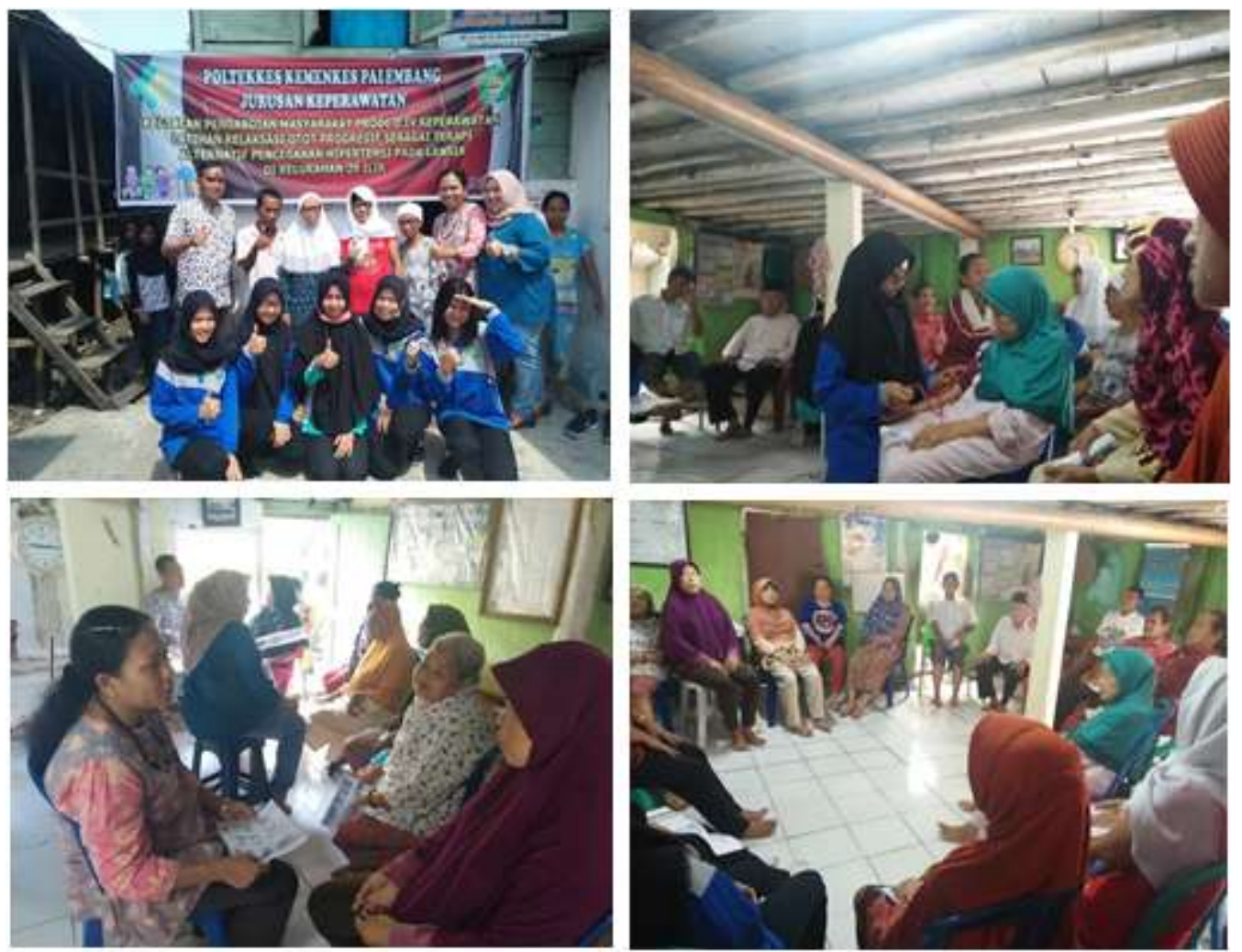

Gambar 1. Demonstrasi, Latihan Otot Progresif, pemeriksaan tekanan darah dan Pendidikan kesehatan

Berdasarkan hasil analisis pengabdi maka dapat disimpulkan bahwa latihan relaksasi otot propgresif memiliki dampak yang signifikan terhadap penurunan tekanan dari responden yaitu sekitar 10-15 mmHg. Tidak hanya itu semua peserta pelatihan mengungkapkan rasa bahagianya setelah melakukan latihan relaksasi otot progresif ini. Hal ini senada dengan penelitian azizah (2011) dan Rosidin dkk, (2019) yang menyatakan bahwa para lansia merasakan perasaan bahagia dan tubuh kembali bugar setelah melakukan relaksasi otot progresif. Perasaan bahagia akan merangsang zat-zat seperti serotonin (sebagai vasodilator pembuluh darah) dan hormon endorphin yang bisa memperbaiki tekanan darah lebih lancar dan berkontribusi pada penurunan tekanan darah.

Adanya hasil terhadap penurunan tekanan darah dari kegiatan pengabdian masyarakat ini menunjukkan terdapat pengaruh teknik relaksasi otot progresif terhadap tekanan darah pada penderita hipertensi di RT 13 Kelurahan 29 Ilir Kecamatan Ilir Barat II Palembang, makahasil pengabdian masyarakat ini dapat bermanfaat sebagai salah satu intervensi yang dapat dilaksanakan dalam penatalaksanaan penderita hipertensi secara non farmakologi.

Relaksasi otot progresif merupakan salah satu terafi non farmakologi dalam mengatasi hipertensi yang relative mudah di aplikasikan dan tidak membutuhkan biaya yang besar, namun kita memperoleh hasil yang bermakna terhadap penurunan tekanan darah baik systole maupun diastole bagi penderita hipertensi.Oleh karena itu latihan relaksasi otot progresif menjadi pilihan pertama yang dapat dilakukan untuk mengelola hipertensi. Dalam latihan relaksasi otot progresif, gerakan menegangkan sekumpulan otot dan kemudian melemaskannya serta 
membedakan sensasi tegang dan rileks, seseorang tersebut dapat menghilangkan

\section{KESIMPULAN}

Dari hasil evaluasi dan temuantemuan yang pengabdi peroleh selama pelaksanaan kegiatan pengabdian masyarakat ini, dapat disimpulkan bahwa program pengabdian masyarakat ini telah mampu memberikan manfaat bagi masyarakat di RT 13 Kelurahan 29 Ilir, Kecamatan Ilir Barat II Kota Palembang yang menjadi sasaran kegiatan ini. Bentuk penyuluhan sekaligus pelatihan langsung kepada masyarakat ini merupakan bentuk yang efektif untuk memberikan penyegaran dan wawasan baru bagi masyarakat khususnya pasien hipertensi dalam menurunkan tekanan darah dengan latihan relaksasi otot progresif. Masyarakat yang menderita Penyakit Hipertensi memperoleh alternatif dalam mengatasi penyakit yang dideritanya selain therapy obat hipertensi yaitu Latihan Relaksasi Otot Progresif. Latihan Relaksasi Otot

\section{DAFTAR PUSTAKA}

Azizah, L. M. R. (2011). Keperawatan lanjut usia. Yogyakarta: Graha Ilmu, 45.

Adisucipto, (2014). Pengaruh relaksasi otot progresif terhadap tekanan darah pada lansia dengan Hipertensi di Desa Karangbendo Banguntapan Bantul Yogyakarta. Skripsi. Yogyakarta

Herawati, Isnaini dan Siti Nur Azizah (2016). Effect of Progressive Muscle Relaxation Exercise to Decrease Blood Pressure for Patients with Primary Hypertension. International kontraksi otot untuk selanjutnya akan mengalami perasaan rileks dan nyaman.

Progresif dapat dilakukan diberbagai temapat seperti dirumah, dan dapat dilakukan dengan persiapan yang sederhana, murah dan dapat menurunkan tekanan darah 5-10 mmHq jika dilakukan dengan sungguh sungguh. disarankan hendaknya program-program pengabdian masyarakat seperti ini dilakukan secara reguler dan berkala mengingat kebutuhan masyarakat akan terapi alternatif disamping terapi medis dalam mengatasi penyakit non menular seperti hipertensi. Selain itu diharapkan, disamping kader agar petugas puskesmas lebih aktif lagi terjun langsung ke masyarakat dalam mendampingi kegiatan-kegiatan seperti ini agar petugas puskesmas juga dapat membantu mensosialisasikan terapi komplementer seperti relaksasi otot progresif guna dimasukkan kedalam program-program puskesmas

\section{Conference on Health and Well- Being (ICHWB)}

Kumutha, S. Aruna and R. Poongodi (2014). Effectiveness of Progressive MuscleRelaxation Technique on Stress and Blood Pressure among Elderly with Hypertension. IOSR Journal of Nursing and Health Science, vol. III, no. 4, pp. 1-6.

LeMone, P., Burke, K,. (2015). Medical Surgical Nursing: Critical Thinking in Client Care, 4th Ed. New Jersey. Persone Prentice Hall. 
Muttaqin, A. (2012) Asuhan Keperawatan Klien Dengan Gangguan Sistem Kardiovaskular. Jakarta: Salemba Medika.

Padila. (2013). Asuhan keperawatan Penyakit Dalam. Yogyakarta: Nuha Medika.

Pamungkas, Rian A., Wahyu Kirana, dan Florensa. (2016). Relaxation Progressive Muscle Program on Exercise Behaviorand Clinical Outcomes among Hypertension Patients. International Journal of Public Health Science (IJPHS), Vol.5, No.4, pp.400-405.

Purwanto, B. (2013).Herbal dan Keperawatan Komplementer. Yogyakarta: Nuha Medika.

Ranita, R., Gurmeet S., dan Dicky. (2011). Naskah Lengkap Pertemuan Ilmiah Tahunan Ilmu Penyakit Dalam 2011. Jakarta: Interna Publishing.

Ramadi, A. (2012). Perbedaan pengaruh pemberian seduhan daun alpukat (persea gratissima gaerth) terhadap tekanan darah pada pasien hipertensi laki-laki yang perokok dengan bukan perokok di wilayah kerja Puskesmas Padang Pasir Kota Padang tahun 2012. Padang: Skripsi Universitas Andalas.

Resti, Indriana Bil. (2014). Teknik Relaksasi Otot Progresif untuk Mengurangi Stres pada Penderita
Asma.Jurnal Ilmiah Psikologi Terapan, Vol.02, No.01.

Rosidin, U., Sumarni, N., \& Suhendar, I. (2019). Penyuluhan tentang Aktifitas Fisik dalam Peningkatan Status Kesehatan. Media Karya Kesehatan, 2(2).

Triyanto. (2014). Pelayanan keperawatan bagi Penderita Hipertensi Secara Terpadu. Yogyakarta: Graha Ilmu.

Tyani, Endar S., Wasisto Utomo, dan Yesi Hasneli N. 2015. Efektifitas Relaksasi Otot Progresif terhadap Tekanan Darah pada Penderita Hipertensi Esensial.JOM Vol.2 No.2, 10.

World Health Organization. (2013). High Blood Pressure: a Public Health Problem: World Health Day 2013. Diakses pada 27 Desember 2017, dari

http://apps.who.int/iris/bitstream/106 65/113242/1/Fact_Sheet_WHD_201 3_EN_14870.pdf?ua=1.

Valentine, D. A., Kp, S., Kes, M., Saparwati, M., \& Kep, M. (2013). Pengaruh Teknik Relaksasi Otot Progresif Terhadap Tekanan Darah pada Lansia Dengan Hipertensi di Kel.Pringapus, Kec. Pringapus Kab. Semarang 1. Journal of Science, $4(1) ; 1-7$. 